\title{
Legitimidade das organizações da sociedade civil: análise de conteúdo à luz da teoria da capacidade crítica
}

\author{
Morgana G. Martins Krieger \\ Instituto Nossa Ilhéus \\ Carolina Andion \\ Universidade do Estado de Santa Catarina
}

\begin{abstract}
Este artigo visa a ampliar a compreensão do fenômeno da legitimidade das organizações da sociedade civil (OSC), interpretando-o à luz da teoria da capacidade crítica, de Boltanski e Thévenot (2006). Mais especificamente, trata-se de identificar, por meio da análise do discurso de atores representativos do campo, quais são as justificativas que embasam a atuação e a existência das OSC, conferindo-lhes legitimidade. Tomando por base a fundamentação teórica e a análise da trajetória do campo no Brasil, algumas hipóteses foram formuladas: 1) que diversas lógicas são utilizadas nas justificativas; 2) que o encontro dessas lógicas provoca disputas e conflitos; 3) que possibilita a construção de passarelas; e 4) que existem lógicas predominantes que isolam a existência das outras. Por meio de análise de conteúdo do discurso de 46 atores representativos do campo das OSC na região Sul do Brasil, as hipóteses foram testadas e concluiu-se que as dimensões predominantes da legitimidade nessas OSC são a pragmática e a moral, as quais estimulam a adaptação das OSC a padrões estabelecidos externamente, enfraquecendo a pluralidade e, por conseguinte, a democracia no campo.
\end{abstract}

Palavras-chave: organização da sociedade civil; legitimidade; teoria da capacidade crítica; democracia.

Legitimidad de las organizaciones de la sociedad civil: análisis de contenido a la luz de la teoría de la capacidad crítica

Este artículo objetiva ampliar la comprensión del fenómeno de la legitimidad de las organizaciones de la sociedad civil (OSC), interpretándolo a la luz de la teoría de la capacidad crítica, de Boltanski y Thévenot (2006). Más específicamente, se trata de identificar, por medio de análisis del discurso de actores representativos del campo, cuáles son las justificativas que apoyan la actuación y la existencia de las OSC, dándoles legitimidad. Teniendo como base el fundamento teórico y el análisis de la trayectoria del campo en Brasil, se formularon algunas hipótesis: 1) que varias lógicas son utilizadas en las justificativas; 2) que

Artigo recebido em 13 jan. 2013 e aceito em 11 nov. 2013. 
la reunión de esas lógicas provoca disputas y conflictos; 3) que posibilita la construcción de pasarelas; y 4) que hay lógicas predominantes que aíslan la existencia de las otras. Por medio de análisis del contenido del discurso de 46 actores representativos del campo de las OSC en la región Sur de Brasil, las hipótesis fueron probadas y se concluyó que las dimensiones predominantes de la legitimidad en esas OSC son la pragmática y la moral, que estimulan la adaptación de las OSC a estándares establecidos externamente, debilitando la pluralidad y, por lo tanto, la democracia en el campo.

Palabras clave: organización de la sociedad civil; legitimidad; teoría de la capacidad crítica; democracia.

Legitimacy of civil society organizations: content analysis in the light of the critical capacity theory

This article aims to broaden understanding of the phenomenon of legitimacy of civil society organizations (CSOs), interpreting it in the light of the critical capacity theory, proposed by Boltanski and Thévenot (2006). More specifically, it identifies, by means of discourse analysis of representative actors from the field, which are the justifications supporting the action and existence of CSOs, providing them with legitimacy. Having as a basis the theoretical framework and an analysis of the trajectory of the field in Brazil, some hypotheses were formulated: 1) that several reasonings are used in the justifications; 2) that the meeting between these reasonings provokes disputes and conflicts; 3 ) that it enables constructing footbridges; and 4) that there are predominant reasonings isolating the existence of other ones. Through discourse content analysis of 46 representative actors of the field of CSOs in the Brazilian South region, the hypotheses were tested and we found out that the predominant legitimacy dimensions in these CSOs are the pragmatic and moral, which stimulate the adaptation of CSOs to externally set standards, making plurality and, thus, democracy in the field weaker.

KeYWORDs: civil society organization; legitimacy; critical capacity theory; democracy.

\section{Introdução}

Nas últimas décadas, as organizações da sociedade civil (OSC) vêm assumindo novos papéis na esfera pública brasileira e isso vem proporcionando mudanças na sua identidade e transformando suas fontes habituais de legitimidade. Como destaca Landim (2002), tradicionalmente, as OSC definiram sua identidade por meio de conexões muito bem delimitadas (com a Igreja, com movimentos sociais, com a cooperação internacional), e isso de certa forma garantia a elas legitimidade. Entretanto, essa situação muda na atualidade.

A esfera pública brasileira se altera consideravelmente a partir dos anos 1990 e isso traz novos dilemas e desafios que influenciam no papel e na identidade das OSC (Abramovay, 2000; Andion, 2007; Landim, 2002). Para ilustrar algumas dessas transformações, observa-se que, do conjunto de 338 mil associações e fundações brasileiras, 67,8\% foi criada a partir dos anos 1990, quando houve uma forte ampliação do campo (IBGE, 2008), principalmente pela inserção do meio empresarial, com o Investimento Social Privado e a Responsabilidade Social. Por outro lado, as OSC pioneiras, sejam aquelas com um perfil mais político ou as filantrópicas, também redefiniram sua identidade, se demarcando dos movimentos sociais e da Igreja. De fato, atualmente, as OSC passam a atuar numa esfera pública mais plural e complexa, com 
múltiplos interlocutores, fruto dos processos de democratização e de descentralização, e na qual novos instrumentos jurídicos e institucionais levam a uma maior aproximação entre as OSC, o Estado e o mercado.

Nessa redefinição das relações com o meio em que atuam e do qual são nutridas, as OSC tornam-se também alvo de críticas. Quem, que interesses e que valores elas representam? Quais os resultados que produzem? Quais os seus reais papéis na sociedade? Essas e outras questões se multiplicam tanto na esfera da opinião pública quanto no meio acadêmico. Algumas OSC são questionadas por se transformarem em "agências prestadoras de serviços para órgãos estatais e empresas privadas" (Quadros, 1998:11), enfraquecendo sua autonomia e inovação. Transparência e accountability também são alvos de críticas (Brown e Jagadananda, 2007; Gibelman e Gelman, 2004; McGann e Johnstone, 2005), bem como a capacidade de representar e defender valores. Diferentes autores apontam que elas não respondem necessariamente aos grupos mais excluídos e que muitas vezes são influenciadas por valores diferentes dos quais professam (Brown e Jagadananda, 2007; Slim, 2002; Taylor e Warburton, 2003).

Neste cenário, a legitimidade das OSC é colocada em xeque. Legitimidade é aqui compreendida como a percepção generalizada de que uma organização tem o direito de ser e fazer algo na sociedade, tendo suas ações julgadas como apropriadas, de acordo com um sistema normativo e com base em justificações para a sua ação política e social (Atack, 1999; Edwards, 2000; Krieger, 2011; Suchman, 1995).

Tendo como objetivo aprofundar o tratamento do conceito de legitimidade das OSC, para além de uma visão funcionalista — com vistas a compreender: (i) como se dá a formação da percepção pública que forma essa legitimidade; (ii) como acontecem as relações entre os atores no campo; e (iii) como essas relações interagem produzindo críticas e confrontos e/ ou levando a acordos que têm por base justificações consideradas legítimas — partimos de uma aproximação do debate sobre a legitimidade das OSC com a teoria da capacidade crítica (Boltanski e Thévenot, 2006; Boltanski e Chiapello, 2009), teoria abordada sinteticamente na primeira parte deste artigo.

Essa aproximação entre as teorias da legitimidade das OSC e a teoria da capacidade crítica, que será explorada na segunda parte deste artigo, nos permitiu construir um Quadro de Análise para a pesquisa (quadro 3), além de possibilitar a inferência de algumas hipóteses, também com base na análise da trajetória histórica do campo das OSC no Brasil.

O Quadro de Análise orientou a pesquisa de campo que foi conduzida utilizando-se da técnica de análise de conteúdo organizada em torno de três fases: "a pré-análise; a exploração do material; e o tratamento dos resultados, a inferência e a interpretação" (Bardin, 1977:121). Na pré-análise, além da definição da problemática do estudo, da concepção do quadro analítico e do levantamento das hipóteses, foi feita a delimitação da amostra da pesquisa e elaborados os questionários. Foram pesquisadas 37 OSC da região Sul do Brasil escolhidas por meio de amostra intencional representativa definida: (i) segundo critérios de relevância: tempo de atuação, grau de articulação e credibilidade nos setores em que atuavam (Godoi e Mattos, 2006; Alves-Mazzotti e Gewandsznajder; 1999) e (ii) levando em conta a tipologia que define os principais grupos de OSC que compõem o campo, estabelecida por Andion (2007).

Em cada uma das capitais dos estados do Sul do Brasil (Curitiba, Florianópolis e Porto Alegre) foram selecionadas OSC que representassem cada um dos tipos definidos na tipologia 
de Andion (2007), de modo a considerar a diversidade do campo: (i) OSC históricas de assessoria a movimentos sociais (como movimento popular - uma, sindicato - uma, e de luta pela terra - uma); (ii) OSC mais recentes ligadas aos Novos Movimentos Sociais (como o movimento LGBTS - uma, movimento negro - uma, a agroecologia - uma, e de defesa dos direitos de crianças e adolescentes - uma); (iii) OSC com perfil mais técnico (voltadas para a promoção do voluntariado, do empreendedorismo ou da formação profissional - 10); (iv) OSC ligadas ao Investimento Social Privado (10) e OSC com perfil mais filantrópico e ligado à Igreja (10). Nestas organizações foram entrevistados os gestores e/ou técnicos responsáveis pela gestão das atividades/projetos (sendo eles remunerados ou voluntários).

Além dos próprios membros das OSCs, foram também entrevistados nove atores com papel de formação no campo (consultores, professores, pesquisadores). Ao total, foram entrevistados 46 atores, sendo 16 no Paraná (Curitiba), 15 no Rio Grande do Sul (Porto Alegre) e 15 em Santa Catarina (Florianópolis), entre setembro e novembro de 2010. Foram utilizados roteiros estruturados com perguntas específicas para cada grupo de atores (membros das OSC e formadores), com base no Quadro de Análise. Todas as entrevistas foram depois transcritas em sua íntegra.

A codificação dos dados, que corresponde à fase de exploração do material (Bardin, 1977), foi realizada com o suporte do software Nvivo 9 e ocorreu por meio da alocação dos trechos das entrevistas no Quadro de Análise (quadro 3). O software também foi utilizado para realizar o tratamento dos resultados e buscar as interpretações.

O tratamento dos dados se deu por meio dos seguintes passos: (i) contagem de palavras de cada uma das categorias do Quadro de Análise, de acordo com o grupo de OSC pesquisado; (ii) definição das palavras-chave das entrevistas, de acordo com os "mundos comuns" da teoria da capacidade crítica; (iii) alocação das palavras-chave em cada um dos mundos, de acordo com o Quadro de Análise; (iv) aferição da porcentagem de palavras que os diferentes grupos utilizavam para cada categoria, realizando uma análise frequencial.

Com isso, chegou-se à análise final, apresentada na terceira parte deste artigo, com a identificação dos resultados relativos para cada um dos grupos pesquisados, além da confrontação dos resultados encontrados com as hipóteses, permitindo chegar às considerações finais discutidas na última parte do texto.

\section{Breve incursão na teoria da capacidade crítica}

Boltanski e Thévenot são os precursores da teoria da capacidade crítica (TCC), ${ }^{1}$ integrante da chamada sociologia pragmática francesa. ${ }^{2} \mathrm{Na}$ obra fundadora De la justification: les économies

\footnotetext{
${ }^{1}$ Optou-se aqui por utilizar a denominação teoria da capacidade crítica (TCC) para tradução da théorie des grandeurs apresentada originalmente no livro De la justification, pois essa foi uma sugestão do próprio Laurent Thévenot, quando consultado por nós. Entretanto, sabe-se que outras traduções são utilizadas no Brasil, tais como teoria pragmática da crítica, teoria das grandezas ou ainda teoria da justificação.

${ }^{2}$ A sociologia pragmática ou sociologia pragmática da crítica consiste em uma vertente analítica formulada como divergência à "sociologia crítica", representada, sobretudo, pela obra de Pierre Bourdieu, e em favor de uma "sociologia
} 
de la grandeur, de 1991, os autores apresentam as seis grandes lógicas de justificação que fundamentam a ação humana. Outra obra fundamental e complementar é Le nouvel esprit du capitalisme, de 1999, de Boltanski e Chiapello, na qual os autores percorrem a história do capitalismo e as justificações utilizadas para aderir à sua lógica, sugerindo uma sétima lógica de justificação da ação.

A TCC parte do imperativo de que a coordenação e a construção de acordos ocorrem com base em processos de legitimação. Para seus autores, os acordos não são duradouros, o que leva os indivíduos a terem de se justificar e de criticar, enquanto participando de sequências de ações rotineiras ou intensificadas por disputas e conflitos. Os indivíduos convivem e fazem acordos por meio da justificação de suas escolhas e ações, em um processo de legitimação. Esta possibilidade de coordenação do comportamento humano é o primeiro pilar da legitimidade.

Os autores destacam a habilidade humana de estabelecer associações entre coisas que são relevantes e de alcançar acordos na forma de generalidades. As associações são formadas na relação com algo mais geral, algo comum a todos e não a fatores unicamente individuais e particulares (Boltanski e Thévenot, 2006). Desse modo, cria-se certa regularidade que permite a coordenação, o que diminui a incerteza e a indeterminação da natureza das situações da vida (Lévesque, Bourque e Forgues, 2001).

Os autores se preocuparam não somente com as formas de associações comuns e comunicáveis, mas com aquelas que podem obter suporte por meio de justificações. Essas justificações, no entanto, não provêm de fontes infinitas. Seguindo argumentos de Aristóteles e de Cícero, parte-se do pressuposto de que as justificações são provenientes de diferentes ordens de grandeza (ordres de grandeur) que estão inseridas em políticas denominadas de cidades (cités). Para acessar essas cidades, Boltanski e Thévenot (2006) se utilizam de obras canônicas da filosofia política. A seguir, no quadro 1 , as cidades e suas definições são resumidamente apresentadas.

\section{Quadro 1 \\ As cidades (cités)}

\footnotetext{
"As cidades, (...), em número de seis, constituem lógicas de ação ou justificações legítimas para reduzir a incerteza no âmago das interações sociais. Boltanski e Chiapello (2009) apresentam uma sétima cidade emergente, construída pelo evidenciamento da literatura administrativa e que corresponde ao surgimento de um novo espírito do capitalismo" (Lévesque, 2007:55).

Cidade Inspirada: Baseada na obra A Cidade de Deus, de Santo Agostinho, tem como princípio superior comum a inspiração. Sua grandeza é demonstrada por aquilo que é inexpressível, maravilhoso, excitante e pode ser acessada quando os indivíduos se liberam de seus laços, hábitos, bens e daquilo que é mundano, fazendo-o pela paixão irracional e pela espontaneidade. A queda acontece quando o indivíduo deseja voltar a seus hábitos, ficando paralisado artisticamente.
}

Continua

da crítica". A sociologia pragmática busca transcender as oposições clássicas da sociologia entre indivíduo e coletivo, entre ator e estrutura, entre interesse e valor e entre racionalidade e norma e convida à construção de novas formas de interpretação da ação humana que levem em conta a pluralidade de modos de engajamento dos seres humanos e não humanos no mundo. Ela recusa a ideia de um indivíduo racional uniforme e focaliza o ator em situação. Desse modo, esforça-se para ultrapassar a separação macro e micro que estruturou durante muito tempo a sociologia. 
Cidade Doméstica: Baseada na obra A política extraída das próprias palavras da Sagrada Escritura, de Bossuet, tem como princípio superior comum a hierarquia e a tradição familiares. Sua grandeza é expressa por aquilo que é superior, bem criado e com bons valores, e o indivíduo superior é responsável pelos inferiores. A queda nesta cidade acontece quando o indivíduo não consegue manter sua boa educação, não sendo mais digno de respeito.

Cidade da Fama: Baseada na obra O Leviatã, de Hobbes, seu princípio superior comum é a opinião pública e sua grandeza é a fama, a visibilidade e o sucesso, que são acessados pelo desejo de ser reconhecido. Para atingir a grandeza, o indivíduo deve estar disposto a publicizar sua vida e as relações entre os indivíduos são baseadas em persuasão e influências. Sua queda acontece quando há indiferença entre os seres, banalidade e falta de reconhecimento.

Cidade Cívica: Inspira-se na obra O contrato social, de Rousseau, e tem como princípio superior comum o bem público e o coletivo. As grandezas são a representatividade, a legalidade, aquilo que é oficial, e são acessadas pela vontade comum de alcançar direitos civis e participação. Para alcançá-las, o indivíduo deve transcender os interesses imediatos e lutar por uma causa, e isto acontece mais harmoniosamente em um Estado de direito. Sua queda acontece quando imperam particularismos e arbitrariedades.

Cidade Mercantil: Inspirada na obra A riqueza das nações, de Adam Smith, tem como princípio superior comum a competição e suas grandezas são os bens desejáveis e valorosos e os sujeitos que são campeões e milionários. O que leva os indivíduos à grandeza é o interesse pelas coisas, o desejo e o egoísmo e para isto eles devem ter desapego e distância emocionais. A evidência desta cidade acontece por meio do lucro, do benefício, dispostos no mercado. Sua queda se dá quando acontece a escravização ao dinheiro.

Cidade Industrial: Baseada na obra Da fisiologia Social, de Saint-Simon, seu princípio superior comum é a eficiência e o desempenho. Sua grandeza se dá pela produtividade e confiabilidade, que são acessadas quando se abre mão da dinamicidade e do risco. A queda acontece quando a humanidade perde sua dignidade em prol da instrumentalização.

Cidade por Projetos: Baseada em um corpus de textos de gestão da década de 1990, tem seu princípio superior comum relacionado aos projetos e à proliferação das redes e conexões. A grandeza está com indivíduos flexíveis e polivalentes, com o papel de conectar os diferentes mundos. O movimento de queda acontece quando há fechamento de redes, apadrinhamentos e privação de elos.

Fonte: Elaborado pelas autoras, a partir das obras de Boltanski e Thévenot (2006) e de Boltanski e Chiapello (2009).

As cidades são então definidas como "ordens de grandezas que sustentam várias construções de filosofia política, dando direção para o senso ordinário do que é justo" (Boltanski e Thévenot, 2006:74). Porém, a TCC não se constrói apenas a partir desses pressupostos metafísicos. Os autores se interessam em compreender como essas ordens de grandeza são utilizadas em situações concretas; ou seja, como elas são mobilizadas pelas pessoas na vida cotidiana para justificar suas ações. Segundo eles: "O acordo se faz em ato, nas provas da realidade, engajando objetos com os quais as pessoas se medem e determinam suas grandezas relativas" (Boltanski e Thévenot, 2006:34).

Assim, os autores saem do âmbito dos princípios metafísicos, que é aquele da filosofia política, e adentram aquele da ação. A TCC visa então desconstruir a oposição entre princípios e práticas, elaborando uma teoria não apenas de argumentos ou do discurso que são confrontados a princípios gerais, "mas que leva em conta o confronto com as circunstâncias, com a 
realidade, ou seja, com o engajamento, de seres humanos e objetos em uma ação" (Boltanski e Thévenot, 2006:163).

Portanto, a qualificação das pessoas e organizações, de acordo com uma ordem de grandeza, não é dada a priori, ela deve ser definida em situação. A realização de uma cidade está sempre condicionada a uma prova de grandeza que permite atribuir os estados às pessoas. As cités embasam os diferentes mundos comuns que são acionados pelas pessoas e colocados à prova nas situações cotidianas. O encontro desses diferentes mundos nem sempre é harmonioso, fazendo com que o processo de justificação e, portanto, de legitimação, seja sempre necessário e provisório.

Com base nesses pressupostos, Boltanski e Thévenot (2006) elaboram um framework para submeter os mundos comuns à prova, o qual foi utilizado na concepção do Quadro de Análise construído para esta pesquisa e apresentado a seguir (quadro 3). Esse framework foi desenvolvido pelos autores para analisar as diferentes gramáticas sobre as quais se baseiam os processos de legitimação. Segundo eles, esse modelo de análise busca compreender a construção de acordos, mas também as controvérsias, as relações entre os humanos e desses com os objetos (não humanos), a relação entre discursos, práticas e situações cotidianas e, sobretudo, leva em conta os processos de justificação e de crítica (Boltanski e Thévenot, 2006).

Um fator-chave do imperativo de justificação é a crítica. Para Boltanski e Thévenot (2006), como as pessoas vivem em uma sociedade complexa e caminham por diversos mundos, estão sujeitas a situações onde são construídos acordos, mas também se produzem disputas e controvérsias, provenientes da crítica. Esta pode surgir por três formas principais: (i) na visualização de objetos estranhos a um mundo específico na situação de um teste, situação esta chamada de desvelamento; (ii) no questionamento da superioridade de um indivíduo que se utiliza de objetos de lógicas diversas para se apresentar como grandioso em um mundo específico; e (iii) no desafio da relação entre o estado de grandeza de um indivíduo e o sacrifício feito por este para alcançar tal estado.

A crítica e as controvérsias estão baseadas no livre arbítrio dos indivíduos, que são capazes de "fechar seus olhos", de resistir às distrações e engajar-se à situação em que estão envolvidos, e também de "abrir seus olhos", de distinguir os objetos que derivam de outro mundo e de desafiar a validade do teste, chegando a um julgamento crítico. Para os autores citados, as habilidades de fechar e abrir os olhos são relevantes para completar passagens entre situações que surgem de mundos diferentes, indispensáveis para conduzir o comportamento humano em uma sociedade complexa.

No entanto, o encontro entre diferentes mundos não resulta somente em críticas, abrindo espaço para a união entre os objetos de mundos distintos, em uma fórmula de compromisso (Boltanski e Thévenot, 2006). Nessas ocasiões, forma-se uma situação composta (uma passarela entre os mundos) na qual as diferentes lógicas são mantidas presentes. O compromisso se dá na construção de passarelas entre os mundos comuns e não mediante a eliminação de suas diferenças: 
Um compromisso sugere a possibilidade de um princípio que pode tomar decisões baseandose em objetos decorrentes de mundos diferentes e fazê-los compatíveis. Ele objetiva a um bem comum que transcende as duas diferentes formas de grandeza presentes através da inclusão de ambas. (Boltanski e Thévenot, 2006:278)

Os compromissos realizados entre dois mundos apresentam certo grau de fragilidade, já que geram uma situação composta não formada sobre a base de um novo princípio superior comum. De acordo com os autores, o modo de solidificar o compromisso é colocando objetos provenientes dos diferentes mundos a serviço do próprio compromisso e encobri-los com uma identidade que não seja mais reconhecida a não ser que eles estejam em conjunto.

\section{Legitimidade das OSC e teoria da capacidade crítica: construindo o quadro de análise}

Fazendo uma breve incursão no debate teórico sobre a legitimidade das OSC, pode-se afirmar que o julgamento do que é legítimo, segundo os diferentes autores, está ligado a alguns fatores que lhes conferem legitimidade: (i) O desempenho e os resultados e/ou impacto de sua atuação (Atack, 1999; Edwards, 2000); (ii) A aceitação dos procedimentos e métodos utilizados e a aderência às regras e normas formais da sociedade (Atack, 1999; Brown e Jagadananda, 2007; Civicus, 2010; Edwards, 2000); (iii) A representatividade e atuação em espaço público (Atack, 1999; Collingwood, 2006; Edwards, 2000; Vedder, 2007); (iv) A causa e os valores expressos pela organização (Atack, 1999; Edwards, 2000). Esses aspectos podem ser relacionados com as três dimensões de legitimidade das organizações apresentadas por Suchman (1995) em seu trabalho fundador: a pragmática, a moral e a cognitiva.

A aproximação dessas diferentes abordagens permite formular uma síntese, fazendo uma correlação entre as correntes, as dimensões, as formas e as estratégias que conferem legitimidade às OSC. Essas, por sua vez, podem ser relacionadas com os diferentes "mundos comuns", apresentadas por Boltanski e Thévenot (2006), conforme apresentado sinteticamente no quadro 2.

Cada um dos tipos de legitimidade baseia-se em lógicas específicas, tendo sua justificação fundamentada em diferentes mundos comuns. Da mesma forma que podem ser construídas passarelas entre os tipos, também podem emergir tensões provenientes do processo de crítica levantado por Boltanski e Thévenot (2006) e corroborado por Ossewaarde, Nijhof e Heyse (2008), que apontam os embates existentes entre os tipos de legitimidade. 
Quadro 2

\section{Relação entre tipos de legitimidade e os mundos comuns}

\begin{tabular}{|c|c|c|c|c|}
\hline $\begin{array}{l}\text { Dimensões da } \\
\text { Legitimidade nas } \\
\text { Organizações }\end{array}$ & $\begin{array}{c}\text { Tipos de } \\
\text { Legitimidade }\end{array}$ & $\begin{array}{c}\text { Aspectos que Conferem } \\
\text { Legitimidade }\end{array}$ & Estratégias & $\begin{array}{l}\text { Mundos } \\
\text { Comuns }\end{array}$ \\
\hline \multirow{2}{*}{$\begin{array}{r}\text { PRAGMÁTICA } \\
\text { (Baseia-se no } \\
\text { autointeresse dos } \\
\text { stakeholders e em } \\
\text { trocas efetivas com os } \\
\text { mesmos) }\end{array}$} & $\begin{array}{l}\text { Eficiência e } \\
\text { resultados. }\end{array}$ & $\begin{array}{l}\text { Avaliação de desempenho } \\
\text { e resultados; comunicação } \\
\text { dos resultados; prestação } \\
\text { de contas financeira e de } \\
\text { resultado; resposta aos } \\
\text { stakeholders. }\end{array}$ & $\begin{array}{l}\text { Informar } \\
\text { stakeholders sobre } \\
\text { atividades, finanças } \\
\text { e resultados } \\
\text { (cálculo de custo e } \\
\text { benefício). }\end{array}$ & $\begin{array}{l}\text { Mundos } \\
\text { industrial e } \\
\text { mercantil. }\end{array}$ \\
\hline & $\begin{array}{l}\text { Aderência a regras e } \\
\text { normas da sociedade. }\end{array}$ & $\begin{array}{c}\text { Cumprimento das } \\
\text { leis; adequação dos } \\
\text { procedimentos às regras e } \\
\text { normas sociais. }\end{array}$ & $\begin{array}{c}\text { Alinhar-se a } \\
\text { normas/padrões } \\
\text { de legitimidade } \\
\text { existentes; relatórios } \\
\text { anuais; acreditações. }\end{array}$ & $\begin{array}{l}\text { Mundos cívico e } \\
\text { industrial. }\end{array}$ \\
\hline \multirow{2}{*}{$\begin{array}{r}\text { MORAL } \\
\text { (Foca na avaliação } \\
\text { normativa da } \\
\text { organização e de } \\
\text { suas atividades) }\end{array}$} & $\begin{array}{l}\text { Representatividade e } \\
\text { formação de espaço } \\
\text { público. }\end{array}$ & $\begin{array}{l}\text { Prestação de contas } \\
\text { geral; transparência; } \\
\text { decisão compartilhada; } \\
\text { representatividade } \\
\text { reconhecida. }\end{array}$ & $\begin{array}{l}\text { Métodos de } \\
\text { accountability e } \\
\text { transparência; } \\
\text { governança } \\
\text { compartilhada. }\end{array}$ & $\begin{array}{l}\text { Mundos cívico e } \\
\text { de projetos. }\end{array}$ \\
\hline & Valores e aceitação. & $\begin{array}{l}\text { Importância e relevância } \\
\text { de sua causa (missão, } \\
\text { valores, objetivos); } \\
\text { credibilidade e confiança } \\
\text { dos públicos. }\end{array}$ & $\begin{array}{l}\text { Ritos, símbolos } \\
\text { e cerimônias; } \\
\text { construção de } \\
\text { novos padrões de } \\
\text { legitimidade. }\end{array}$ & $\begin{array}{l}\text { Mundos da } \\
\text { inspiração, } \\
\text { doméstico e } \\
\text { cívico. }\end{array}$ \\
\hline $\begin{array}{r}\text { COGNITIVA } \\
\text { (Legitimidade varia } \\
\text { de acordo com o } \\
\text { tipo de suporte } \\
\text { prestado pela } \\
\text { sociedade e } \\
\text { pode envolver tanto } \\
\text { apoio afirmativo } \\
\text { quanto aceitação } \\
\text { da organização } \\
\text { como necessária ou } \\
\text { inevitável) }\end{array}$ & & & & \\
\hline
\end{tabular}

Fonte: Elaborado pelas autoras com base nos trabalhos citados. 
Essa aproximação entre o debate sobre a legitimidade das OSC e a teoria da capacidade crítica permitiu uma adaptação do framework desenvolvido por Boltanski e Thévenot (2006) à realidade das OSC para construção do Quadro de Análise da pesquisa (quadro 3). neste sentido, foram utilizadas apenas algumas categorias do framework original que tinham maior relação com a teoria e o fenômeno tratados.

Assim, como base na fundamentação teórica e na análise da trajetória histórica do campo das OSC no Brasil (Andion, 2007; Andion e Serva, 2004; Dagnino, 2002; Gohn, 2007; Fernandes, 1994; Landim, 2002; Scherer-Warren, 2006; Scherer-Warren e Krischke, 1987), partimos do pressuposto de que a legitimidade das OSC não pode ser dada a priori, a partir de uma visão normativa. Isso porque essa legitimidade não se define por forças e fatores exógenos e depende do contexto sócio-histórico no qual as OSC estão inseridas, variando ao longo do tempo e no espaço (Krieger, 2011; Lehr-Lehnardt, 2005; Vedder, 2007).

Desse modo, chegamos às seguintes hipóteses de pesquisa: (i) Há uma multiplicidade de "mundos comuns" e lógicas presentes no campo das OSC, os quais são utilizados para justificar a existência e atuação destas organizações e, portanto, influenciam na sua legitimidade; (ii) há disputas e conflitos entre esses "mundos comuns" e suas lógicas no campo de atuação das OSCs; (iii) passarelas entre os "mundos comuns" podem ser construídas, por meio do diálogo, das redes e de coalizões duradouras e estas poderão fortalecer certas justificações e ideais de legitimidade das OSCs e do próprio campo; (iv) existem lógicas e mundos comuns predominantes no campo que dificultam a existência e isolam outros "mundos comuns". Essas hipóteses foram então testadas empiricamente, a partir da análise de conteúdo do discurso dos atores entrevistados, levando aos resultados apresentados no quadro 3.

\section{Apresentação dos resultados}

\subsection{Os mundos comuns predominantes em cada grupo de OSC no Sul do Brasil}

A análise frequencial das palavras principais presentes no conteúdo das entrevistas dos atores de cada um dos diferentes grupos de OSC resultou nas frequências apresentadas na tabela 1, classificadas de acordo com os mundos comuns e categorias definidas no Quadro de Análise e que são interpretadas a seguir. 


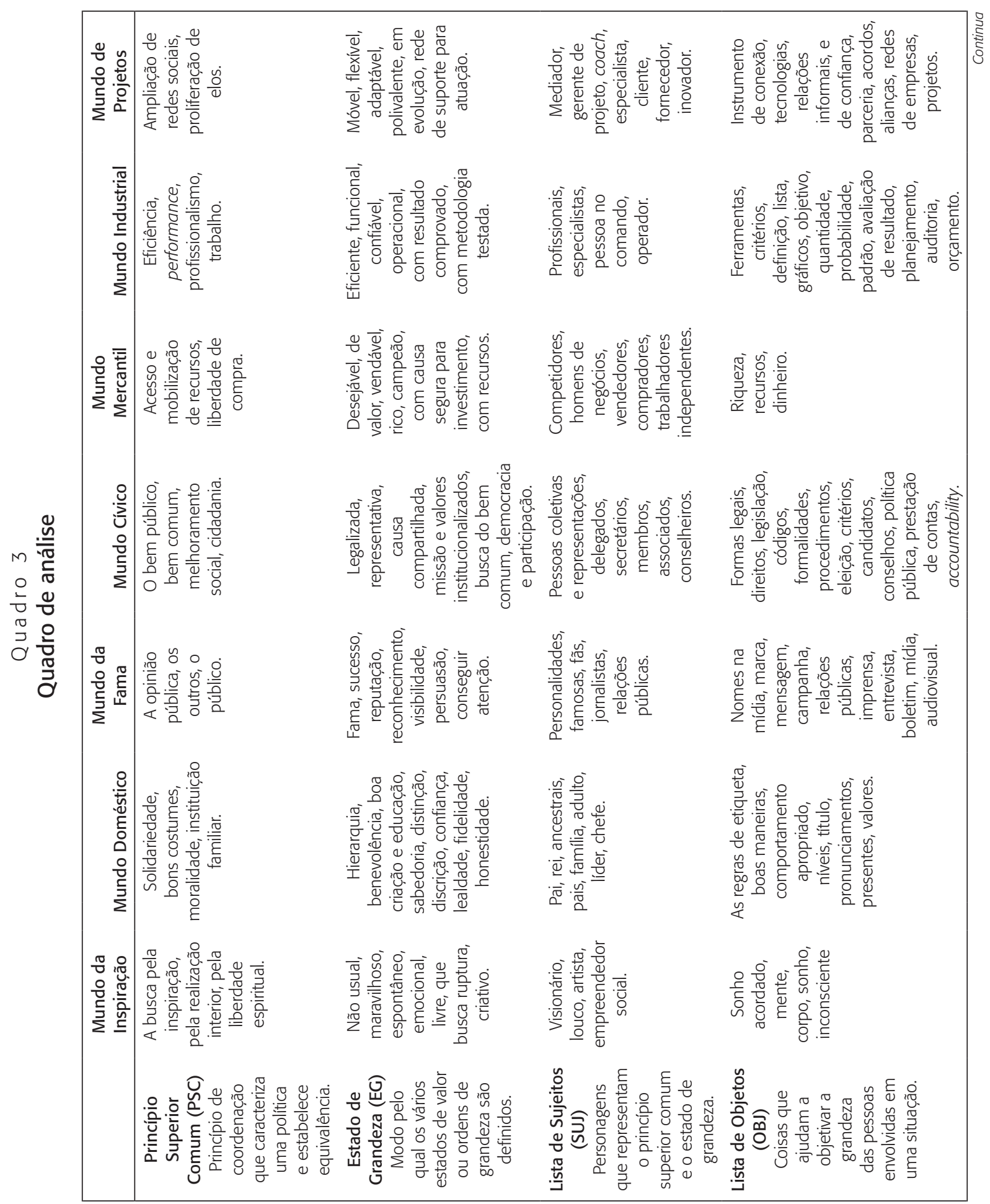

Rev. Adm. Pública - Rio de Janeiro 48(1):83-110, jan./fev. 2014 


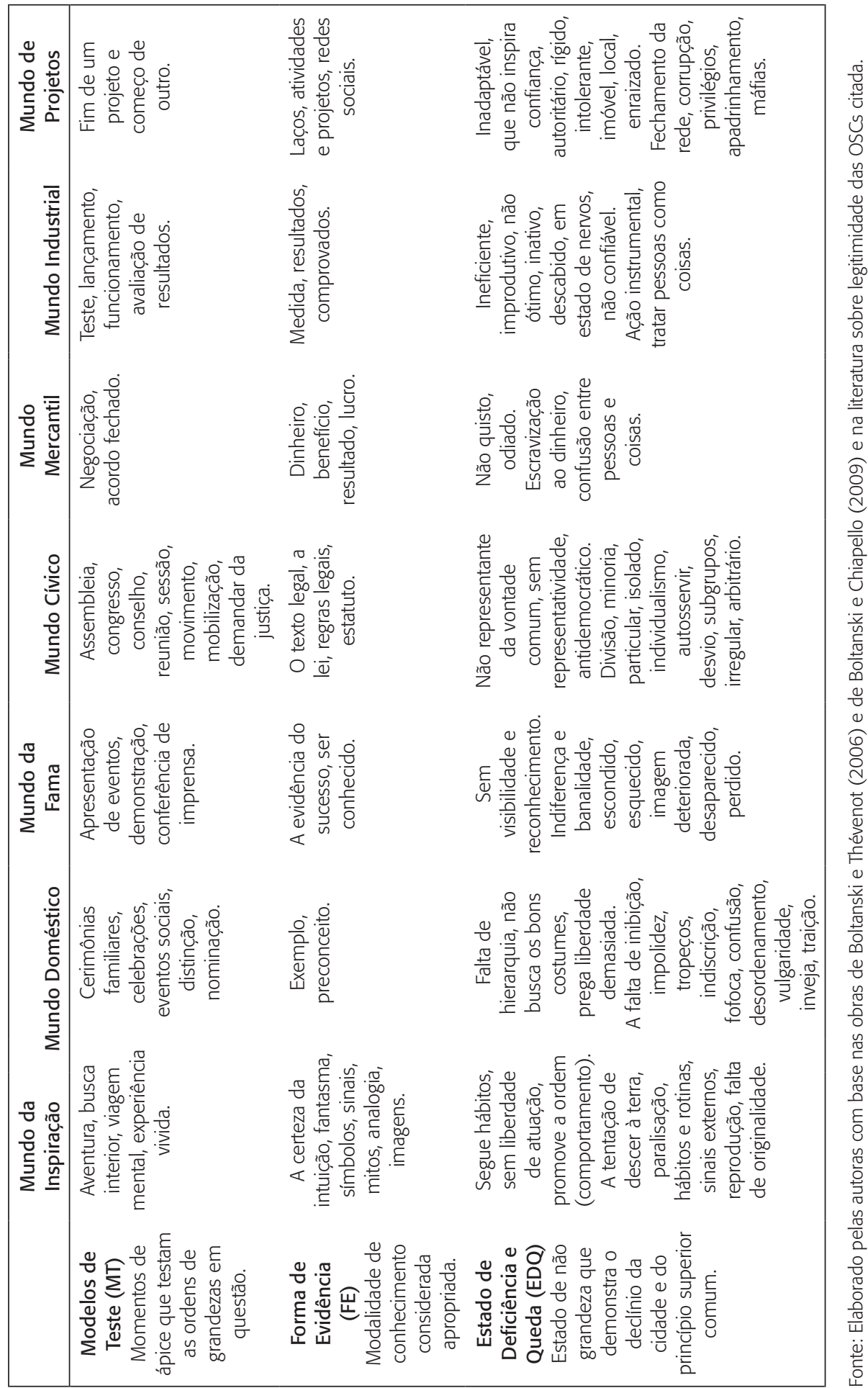

Rev. Adm. Pública - Rio de Janeiro 48(1):83-110, jan./fev. 2014 
Tabela 1

Resultado geral da análise frequencial

\begin{tabular}{|c|c|c|c|c|c|c|c|}
\hline & $\begin{array}{l}\text { Mundo da } \\
\text { Inspiração }\end{array}$ & $\begin{array}{c}\text { Mundo } \\
\text { Doméstico }\end{array}$ & $\begin{array}{l}\text { Mundo da } \\
\text { Fama }\end{array}$ & $\begin{array}{l}\text { Mundo } \\
\text { Cívico }\end{array}$ & $\begin{array}{c}\text { Mundo } \\
\text { Mercantil }\end{array}$ & $\begin{array}{c}\text { Mundo } \\
\text { Industrial }\end{array}$ & $\begin{array}{c}\text { Mundo de } \\
\text { Projetos }\end{array}$ \\
\hline \multicolumn{8}{|c|}{ OSC ligadas aos movimentos sociais } \\
\hline PSC & $1,75 \%$ & $2,45 \%$ & $0,00 \%$ & $66,08 \%$ & $8,57 \%$ & $14,34 \%$ & $6,82 \%$ \\
\hline EG & $0,00 \%$ & $0,00 \%$ & $0,00 \%$ & $78,23 \%$ & $0,00 \%$ & $14,29 \%$ & $7,48 \%$ \\
\hline SUJ & $0,00 \%$ & $6,10 \%$ & $0,00 \%$ & $71,95 \%$ & $0,00 \%$ & $18,29 \%$ & $3,66 \%$ \\
\hline OBJ & $0,62 \%$ & $1,87 \%$ & $0,86 \%$ & $43,95 \%$ & $2,97 \%$ & $37,63 \%$ & $12,10 \%$ \\
\hline FE & $0,00 \%$ & $1,01 \%$ & $1,01 \%$ & $48,15 \%$ & $1,01 \%$ & $39,73 \%$ & $9,09 \%$ \\
\hline MT & $0,00 \%$ & $0,00 \%$ & $0,00 \%$ & $51,56 \%$ & $4,69 \%$ & $37,50 \%$ & $6,25 \%$ \\
\hline EDQ & $0,00 \%$ & $3,36 \%$ & $3,36 \%$ & $71,81 \%$ & $6,04 \%$ & $12,75 \%$ & $2,68 \%$ \\
\hline TOTAL & $0,69 \%$ & $1,97 \%$ & $0,73 \%$ & $53,94 \%$ & $3,94 \%$ & $29,36 \%$ & $9,38 \%$ \\
\hline \multicolumn{8}{|c|}{ OSC filantrópicas } \\
\hline PSC & $1,05 \%$ & $49,30 \%$ & $0,00 \%$ & $25,26 \%$ & $8,60 \%$ & $14,74 \%$ & $1,05 \%$ \\
\hline EG & $5,24 \%$ & $15,73 \%$ & $3,37 \%$ & $26,97 \%$ & $5,62 \%$ & $33,33 \%$ & $9,74 \%$ \\
\hline SUJ & $17,65 \%$ & $16,47 \%$ & $0,00 \%$ & $20,00 \%$ & $11,76 \%$ & $30,59 \%$ & $3,53 \%$ \\
\hline OBJ & $0,82 \%$ & $18,76 \%$ & $1,84 \%$ & $21,48 \%$ & $4,96 \%$ & $45,48 \%$ & $6,66 \%$ \\
\hline $\mathrm{FE}$ & $1,84 \%$ & $37,42 \%$ & $2,86 \%$ & $14,31 \%$ & $3,07 \%$ & $37,42 \%$ & $3,07 \%$ \\
\hline MT & $0,00 \%$ & $1,59 \%$ & $1,20 \%$ & $30,68 \%$ & $2,39 \%$ & $61,35 \%$ & $2,79 \%$ \\
\hline EDQ & $1,69 \%$ & $25,34 \%$ & $1,01 \%$ & $22,30 \%$ & $8,78 \%$ & $35,47 \%$ & $5,41 \%$ \\
\hline TOTAL & $1,78 \%$ & $25,52 \%$ & $1,63 \%$ & $22,22 \%$ & $5,66 \%$ & $38,20 \%$ & $4,99 \%$ \\
\hline \multicolumn{8}{|c|}{ OSC técnicas } \\
\hline PSC & $19,53 \%$ & $3,55 \%$ & $0,00 \%$ & $39,05 \%$ & $12,43 \%$ & $23,67 \%$ & $1,78 \%$ \\
\hline EG & $2,89 \%$ & $9,09 \%$ & $4,55 \%$ & $38,84 \%$ & $16,12 \%$ & $21,07 \%$ & $7,44 \%$ \\
\hline SUJ & $13,46 \%$ & $7,69 \%$ & $0,00 \%$ & $7,69 \%$ & $9,62 \%$ & $61,54 \%$ & $0,00 \%$ \\
\hline OBJ & $3,27 \%$ & $5,31 \%$ & $1,77 \%$ & $15,72 \%$ & 8,63\% & $54,12 \%$ & $11,18 \%$ \\
\hline $\mathrm{FE}$ & $4,04 \%$ & $9,49 \%$ & $2,11 \%$ & 19,33\% & $11,42 \%$ & $47,10 \%$ & $6,50 \%$ \\
\hline MT & 0,00\% & 0,00\% & 0,00\% & $26,92 \%$ & $6,73 \%$ & $56,73 \%$ & $9,62 \%$ \\
\hline EDQ & $2,86 \%$ & $2,14 \%$ & $0,00 \%$ & $24,29 \%$ & $13,57 \%$ & $52,14 \%$ & $5,00 \%$ \\
\hline TOTAL & $4,25 \%$ & $5,83 \%$ & $1,71 \%$ & $20,29 \%$ & $10,27 \%$ & $48,84 \%$ & $8,81 \%$ \\
\hline \multicolumn{8}{|c|}{ OSC ligadas ao investimento social privado } \\
\hline PSC & $2,66 \%$ & $10,65 \%$ & $0,00 \%$ & $33,41 \%$ & $15,50 \%$ & $32,69 \%$ & $5,08 \%$ \\
\hline EG & $0,00 \%$ & $12,97 \%$ & $1,18 \%$ & $17,45 \%$ & $16,51 \%$ & $33,96 \%$ & $17,92 \%$ \\
\hline SUJ & $6,12 \%$ & $10,20 \%$ & $0,00 \%$ & $33,47 \%$ & $10,61 \%$ & $28,57 \%$ & $11,02 \%$ \\
\hline OBJ & $0,00 \%$ & $9,67 \%$ & $1,20 \%$ & $26,80 \%$ & $8,04 \%$ & $41,82 \%$ & $12,46 \%$ \\
\hline FE & $0,36 \%$ & $7,83 \%$ & $1,33 \%$ & $23,98 \%$ & $12,17 \%$ & $42,77 \%$ & $11,57 \%$ \\
\hline MT & $0,00 \%$ & $0,00 \%$ & 0,00\% & $15,89 \%$ & 17,88\% & $52,98 \%$ & $13,25 \%$ \\
\hline
\end{tabular}




\begin{tabular}{|c|c|c|c|c|c|c|c|}
\hline & $\begin{array}{l}\text { Mundo da } \\
\text { Inspiração }\end{array}$ & $\begin{array}{c}\text { Mundo } \\
\text { Doméstico }\end{array}$ & $\begin{array}{l}\text { Mundo da } \\
\text { Fama }\end{array}$ & $\begin{array}{l}\text { Mundo } \\
\text { Cívico }\end{array}$ & $\begin{array}{c}\text { Mundo } \\
\text { Mercantil }\end{array}$ & $\begin{array}{c}\text { Mundo } \\
\text { Industrial }\end{array}$ & $\begin{array}{c}\text { Mundo de } \\
\text { Projetos }\end{array}$ \\
\hline EDQ & $1,14 \%$ & $10,71 \%$ & $2,73 \%$ & $21,87 \%$ & $6,15 \%$ & $47,61 \%$ & $9,79 \%$ \\
\hline TOTAL & $0,74 \%$ & $10,18 \%$ & $1,15 \%$ & $25,40 \%$ & $10,46 \%$ & $40,42 \%$ & $11,66 \%$ \\
\hline \multicolumn{8}{|c|}{ Formadores } \\
\hline PSC & $0,00 \%$ & $2,98 \%$ & $3,07 \%$ & $45,24 \%$ & $2,88 \%$ & $41,21 \%$ & $4,61 \%$ \\
\hline EG & $1,84 \%$ & $13,82 \%$ & $1,38 \%$ & $31,34 \%$ & $9,22 \%$ & $33,18 \%$ & $9,22 \%$ \\
\hline SUJ & $10,26 \%$ & $22,22 \%$ & $0,00 \%$ & $35,90 \%$ & $5,98 \%$ & $22,22 \%$ & $3,42 \%$ \\
\hline OBJ & $0,00 \%$ & $0,70 \%$ & $0,58 \%$ & $20,51 \%$ & $5,68 \%$ & $61,30 \%$ & $11,24 \%$ \\
\hline FE & $2,77 \%$ & $7,27 \%$ & $2,77 \%$ & $9,34 \%$ & $6,57 \%$ & $66,44 \%$ & $4,84 \%$ \\
\hline MT & $0,00 \%$ & $0,00 \%$ & $0,00 \%$ & $18,42 \%$ & $10,53 \%$ & $63,16 \%$ & $7,89 \%$ \\
\hline EDQ & $0,79 \%$ & $3,18 \%$ & $1,75 \%$ & $28,62 \%$ & $7,31 \%$ & $53,42 \%$ & $4,93 \%$ \\
\hline TOTAL & $0,91 \%$ & $4,20 \%$ & $1,85 \%$ & $30,43 \%$ & $5,48 \%$ & $50,34 \%$ & $6,79 \%$ \\
\hline \multicolumn{8}{|c|}{ Resultado Total } \\
\hline TOTAL & $1,69 \%$ & $9,85 \%$ & $1,42 \%$ & $29,12 \%$ & $7,54 \%$ & $41,81 \%$ & $8,56 \%$ \\
\hline
\end{tabular}

Fonte: Dados de campo, 2011.

\subsubsection{OSC ligadas aos movimentos sociais tradicionais e novos}

As organizações ligadas aos movimentos sociais entrevistadas promovem e defendem direitos de LGBTs, de afrodescendentes e de igualdade social, de acesso à terra; apoiam grupos de agricultores rurais e urbanos ou comunidades de base ou ainda atuam com educação popular. A análise permite constatar que esse grupo de organizações possui seus "Princípios Superiores Comuns" (PSC) relacionados ao mundo cívico, definido com termos como "comunidade, direitos, legislação, luta, participação, conselhos". Este trecho de entrevista ilustra essa afirmação: "A gente começa a fazer um trabalho tanto de garantia de direitos a pessoas de religião, ao direito à crença, ao direito ao culto, assim como a defesa da cidadania e a garantia de direitos humanos" (OSC MS 1, 2010).

Os "Objetos" (OBJ), "Formas de Evidência" (FE) e "Modelos de Teste" (MT), apesar de fundamentados na lógica cívica, apresentam grande influência do mundo industrial, demonstrando uma preocupação com a qualidade dos processos, mensuração dos resultados e avaliações às quais as organizações se submetem para legitimar seus resultados.

O "Estado de Deficiência e Queda" (EDQ) está baseado em argumentos da lógica cívica, significando que o enfraquecimento da atuação política e da mobilização social é um forte motivo que levaria ao declínio da organização dentro desta lógica.

Nessa análise, percebe-se uma coerência do discurso destas organizações com a atuação política que as mesmas desenvolvem. Há sobre estas organizações uma pressão da lógica industrial, porém, nota-se, em alguns casos, que essa pressão não resulta apenas em uma 
simples submissão à lógica industrial, mas na construção de passarelas entre as duas lógicas, transcendendo as grandezas presentes em fórmulas de compromisso (Boltanski e Thévenot, 2006). Um exemplo citado foi a prática da "avaliação participativa", um modelo de teste que coloca em relação grandezas do mundo industrial e do mundo cívico.

\subsubsection{OSCs filantrópicas}

As organizações filantrópicas entrevistadas atendem ao público infanto-juvenil, crianças e adolescentes em situação de risco e com doenças, lesões cerebrais e deficiência motora. Elas expressam em seu discurso termos que pertencem principalmente às lógicas dos mundos doméstico, industrial e cívico.

Para definir seu "Princípio Superior Comum" (PSC), essas organizações utilizam termos predominantemente do mundo doméstico, colocando-se como espaços complementares à família, como explicitado no depoimento seguinte:

Uma das causas que é muito importante, e eu estou falando do atendimento de criança, é a falta de estrutura familiar. (...) Eu vejo que esta mudança nos últimos 25 anos do modelo familiar gerou muita dificuldade. Eu vejo os pais muito perdidos, como é que eu faço isto, como é que eu faço aquilo. Porque eles já são frutos de um lar que foi se transformando, que o pai foi embora e que a mãe foi embora, e que trocaram, e que não conseguem se estruturar ainda como família. (OSC FLT 9, 2010)

Quanto ao "Estado de Grandeza" (EG), as falas e os exemplos trazidos pelos atores dividem-se entre as lógicas dos mundos cívico e industrial, demonstrando os processos concomitantes de politização e de profissionalização que se fortalecem nestas organizações atualmente. O mesmo acontece com a "Lista dos Sujeitos" (SUJ) e com as "Formas de Evidência" (FE), com maior ênfase no mundo industrial, mas fazendo referência aos mundos da inspiração e doméstico.

Os termos relativos aos "Objetos" (OBJ) se referem predominantemente ao mundo industrial, assim como os termos ligados aos "Modelos de Teste" (MT), com palavras como "auditoria, avaliação, balancete". Referindo-se ao "Estado de Declínio e Queda" (EDQ), os autores citam falta de "recursos", "má gestão", "desvio financeiro".

A análise dos resultados nos permite constatar que as organizações filantrópicas expressam sua causa principal centrada na lógica doméstica, porém fica evidente a forte influência das lógicas industrial e cívica em sua atuação, com predomínio da primeira. Conforme as entrevistas, percebe-se que essa predominância do mundo industrial acontece principalmente pela aproximação com empresas e institutos/fundações empresariais e também por pressão de formadores que incentivam a profissionalização destas organizações: 
Nós temos um planejamento orçamentário que é feito agora em novembro. (...) Então tem ajudado bastante a administração e o controle de gastos. Isto porque veio um empresário que se apresentou, ele era na verdade um executivo de uma multinacional, ele se interessou pela causa e hoje ele é tesoureiro. Então ele que trouxe esta visão bem de empresa, também, de ter que planejar. (OSC FLT 2, 2010)

A presença de dois ou mais mundos nos "Modelos de Teste" (MT) é comum nas situações cotidianas. Mas, diferentemente do que observamos nas organizações ligadas aos movimentos sociais, onde se dá a construção de passarelas entre dois mundos, no discurso das filantrópicas visualizamos uma clara distância entre as práticas e os princípios superiores comuns. Esse gap poderia então ser gerador de críticas entre esses mundos, revelando uma "desarmonia entre os estados de grandeza e a natureza dos objetos engajados no teste" (Boltanski e Thévenot, 2006:219). Porém, essas críticas não aparecem na fala e nos exemplos dados pelos atores. As evidências indicam que, para tornarem-se legítimas, as OSC filantrópicas, ao invés de desvelar as controvérsias ou criticar as incoerências no encontro dos mundos, têm buscado adaptar suas práticas à lógica do mundo industrial.

\subsubsection{OSC técnicas}

As organizações técnicas entrevistadas atuam com inserção profissional e econômica, promoção de voluntariado e do empreendedorismo e prestação de serviços em áreas sociais, ambientais e de educação. Em seu discurso, essas organizações enfatizam as lógicas do mundo cívico e do mundo industrial.

O "Princípio Superior Comum" (PSC) das organizações técnicas fundamenta-se no mundo cívico, mas percebe-se também explícita influência do mundo industrial. Na fala dos atores, a finalidade cívica parece subordinada aos meios técnicos: "A gente mobiliza e conscientiza o voluntário que vem aqui para que ele vá lá e atenda as demandas daquela causa. E quanto mais estas causas puderem estar resolvidas então melhor será" (OSC TEC 5, 2010). A mesma situação acontece na caracterização dos "Estados de Grandeza" (EG), priorizando os termos do mundo cívico, mas tendo grande influência dos mundos industrial e mercantil.

Já na definição "Lista de Sujeitos" (SUJ), na "Lista dos Objetos" (OBJ), nas "Formas de Evidência" (FE), nos "Modelos de Teste" (MT) e no "Estado de Declínio e Queda" (EDQ), predomina o mundo industrial com termos como "profissional, qualidade, orçamento, metodologia, indicadores, relatórios e crescimento".

A aferição destes resultados permite constatar que as OSCs técnicas almejam transformações sociais por meio da utilização de métodos técnicos e industriais. Neste grupo, as justificações referentes aos princípios e valores têm relação com o mundo cívico, porém na prática se evidencia a lógica do mundo industrial. No discurso dos atores parece não haver "choque" ou críticas aparentes entre esses mundos. 


\subsubsection{OSC ligadas ao investimento social privado}

As organizações entrevistadas deste grupo foram fundações e institutos empresariais com ações em áreas educacionais, sociais, ambientais e de geração de renda. Os resultados obtidos demonstram que essas organizações apresentam a maior parte de seu discurso ligada à lógica do mundo industrial.

As justificações ligadas ao "Princípio Superior Comum" (PSC) e à "Lista de Sujeitos" (SUJ) se encontram divididas entre as lógicas dos mundos cívico e industrial. Quando se referem ao "Estado de Grandeza" (EG), estas organizações apresentam na maioria de seus argumentos palavras pertencentes ao mundo industrial, observando-se também a presença da lógica do mundo de projetos.

A "Lista de Objetos" (OBJ) apresenta a grande maioria de suas referências ligadas ao mundo industrial, assim como as "Formas de Evidência" (FE), seus "Modelos de Teste" (MT) e o "Estado de Declínio e Queda" (EDQ), como exemplificado neste trecho: "A gente sempre apresenta o relatório anual, e a gente coloca o relatório de prestação de contas, tanto do ano passado como também o planejamento e o orçamento para o ano que está em curso, que está vindo" (OSC ISP 7, 2010).

Com lógicas muito semelhantes às organizações técnicas, as organizações ligadas ao investimento social privado também ressaltam o mundo cívico quando se referem a princípios mais gerais e o mundo industrial quando questionadas sobre práticas de atuação. Considerando que essas organizações possuem grande influência no campo, sendo financiadoras ou oferecendo suporte técnico, a predominância do mundo industrial tem papel decisivo para o fortalecimento desta lógica no campo como um todo.

\subsubsection{Formadores}

Os formadores entrevistados atuam na formação de profissionais para o campo, por meio da produção de conhecimento, prestação de serviços, consultoria e cursos de especialização. Atuam, em sua maioria, em instituições de ensino superior com núcleos que atendem às organizações da sociedade civil por meio de ensino, pesquisa e extensão e também em organizações que prestam serviços de consultoria e capacitação na área.

Os formadores referem-se ao "Princípio Superior Comum" (PSC) relacionando-o à lógica do mundo cívico e à do mundo industrial. Os termos utilizados da lógica cívica se voltam para palavras como "social, sociedade, políticas públicas, movimentos sociais, democracia, luta, direito, participação e mudança". Já os termos do mundo industrial utilizados se referem a "desenvolvimento, responsabilidade, instrumentos, formação, recursos, capacidade, curso, processos e gestão".

Quanto à "Lista dos Sujeitos" (SUJ), os formadores se referem principalmente ao mundo cívico, mas as porcentagens relativas ao mundo doméstico e ao mundo industrial são relevantes. Os termos referentes à "Lista de Objetos" (OBJ), às "Formas de Evidência" (FE), aos 
"Modelos de Teste" (MT) e ao "Estado de Deficiência e Queda" (EDQ) correspondem, em sua grande maioria, a termos pertencentes à lógica do mundo industrial.

O discurso predominante nas organizações formadoras denota a presença dos mundos cívico (quando se referindo a princípios) e industrial (quando se referem a estratégias e instrumentos), demonstrando novamente a distância entre os valores defendidos e a prática cotidiana. No entanto, percebe-se nos depoimentos dos formadores a presença de alguns objetos híbridos que apontam compromissos entre os mundos. Um exemplo é o termo "desenvolvimento institucional" citado por alguns formadores como conceito-chave na definição de seu papel no campo das OSC. Os termos "desenvolvimento" e "institucional" se juntam para designar processos que favorecem a sustentabilidade das organizações no sentido de fortalecer seu projeto sociopolítico e não apenas de promover sua profissionalização.

\subsection{Retornando às hipóteses da pesquisa}

\subsubsection{Multiplicidade de mundos e lógicas presentes no campo no Sul do Brasil}

Partindo do pressuposto de que vivemos numa sociedade complexa, na qual os indivíduos possuem competências para circular em situações provenientes de mundos distintos (Boltanski e Thévenot, 2006), e analisando a trajetória sócio-histórica do campo no Brasil, chegamos à hipótese de que existe uma multiplicidade de mundos comuns e lógicas presentes nas justificações do campo das OSC no Sul do Brasil, influenciando sua legitimidade. Essa hipótese se verifica nos dados levantados pela pesquisa. Apesar do predomínio dos mundos industrial e cívico nas justificações, a relevância dos demais mundos não pode ser subestimada, pois os atores se utilizam de elementos pertencentes às diversas lógicas para justificar suas ações em diferentes situações.

A lógica do mundo da inspiração - que foi uma importante fonte de legitimação na origem do campo das OSC do Brasil — ainda hoje tem sua relevância, expressa, por exemplo, na ideia de dedicação incondicional a uma causa valorizada em muitos discursos: "Ah, eu admiro a Zilda Arns, da Pastoral da Criança. Que coisa espetacular. Aquela mulher era a Madre Teresa de Calcutá, um exemplo de bondade, de negação, de doação, sabe" (OSC FLT 4, 2010).

O mundo doméstico, apesar de apresentar características de "Estado de Declínio e Queda" (EDQ) no campo das OSC pesquisadas, demonstra sua relevância nas relações familiares, no afeto, no atendimento ao próximo e na ênfase da diminuição da pobreza e da atenção aos públicos mais excluídos e marginalizados.

O mundo da fama apresenta sua expressão nas ações realizadas pelas OSC para transformar a opinião pública, como eventos, campanhas e paradas.

Já a lógica do mundo mercantil parece adquirir maior relevância no campo social nos últimos anos, devido à aproximação das OSC com o ambiente empresarial, pela ênfase na captação de recursos e na atuação de organizações que promovem o desenvolvimento econômico e a inserção social pelo trabalho. 
Por último, a lógica do mundo de projetos também se desenvolveu nos últimos anos tendo papel relevante na concepção de trabalho em rede e na busca de articulações intersetoriais no campo social.

Conclui-se que a legitimidade das OSC no Sul do Brasil, com pesos diferenciados, tem por base justificações que se referem aos diferentes mundos comuns considerados no Quadro de Análise da pesquisa.

\subsubsection{As disputas entre os mundos comuns no campo no Sul do Brasil}

Boltanski e Thévenot (2006) afirmam que o encontro de diferentes mundos em uma situação pode gerar controvérsias e disputas, levando-nos à hipótese de que existem disputas e conflitos explícitos entre os mundos comuns no campo de atuação das OSCs no Sul do Brasil. De acordo com os autores, os conflitos acontecem principalmente quando objetos estranhos a um mundo são visualizados na situação de um teste ou quando há o questionamento da justificação, estando esta baseada em grandezas de outro mundo comum.

Apesar de essas situações de controvérsias estarem evidentes em alguns grupos de OSC estudadas, elas não aparecem como alvos de críticas por parte dos atores entrevistados. As filantrópicas, por exemplo, possuem sua causa voltada para o mundo doméstico e seus objetos de atuação e testes de julgamento baseados na lógica industrial. No entanto, ao invés de questionar a lógica do teste sendo aplicado e demandar a realização de novos testes alinhados aos seus próprios princípios superiores, esse grupo parece se adaptar aos modelos de teste exigidos. Na busca de legitimação, elas "fecham os olhos" (Boltanski e Thévenot, 2006) para objetos pertencentes a um mundo diferente e engajam-se na situação.

Ao "fecharem os olhos", estas OSC não trazem à tona a controvérsia e não promovem a crítica, o que talvez enfraqueça a necessidade de justificação e a possibilidade de reconhecimento da sua legitimidade, com base nas suas próprias grandezas, e fortaleça o conformismo e a homogeneidade das organizações.

A mesma incoerência, porém em menor grau, acontece nas organizações técnicas e nas ligadas ao investimento social privado, nas quais os "Modelos de Teste" (MT) correspondem, na sua maioria, a uma lógica diferente do Princípio Superior Comum (PSC) priorizado. Com isso, corre-se o risco de a causa política ser apenas um mote para a mobilização e para legitimação do discurso, pois na situação concreta essa lógica é submetida ao mundo industrial.

Os "Modelos de Teste" (MT) aos quais as OSC do Sul do Brasil são submetidas (tabela 2), de acordo com os atores entrevistados, pertencem na sua maioria ao mundo industrial, deixando claro que todas as organizações se submetem a testes desta lógica para justificar suas ações e serem consideradas legítimas. Destaca-se que as organizações ligadas aos movimentos sociais, por apresentarem críticas à lógica industrial e por terem seus testes ligados prioritariamente ao mundo cívico, apresentam esta submissão em menor grau. 
Tabela 2

Modelos de teste por grupo e por mundo comum

\begin{tabular}{|lccccccc|}
\hline & $\begin{array}{c}\text { Mundo da } \\
\text { Inspiração }\end{array}$ & $\begin{array}{c}\text { Mundo } \\
\text { Doméstico }\end{array}$ & $\begin{array}{c}\text { Mundo da } \\
\text { Fama }\end{array}$ & $\begin{array}{c}\text { Mundo } \\
\text { Cívico }\end{array}$ & $\begin{array}{c}\text { Mundo } \\
\text { Mercantil }\end{array}$ & $\begin{array}{c}\text { Mundo } \\
\text { Industrial }\end{array}$ & $\begin{array}{c}\text { Mundo de } \\
\text { Projetos }\end{array}$ \\
\hline MS & $0,00 \%$ & $0,00 \%$ & $0,00 \%$ & $51,56 \%$ & $4,69 \%$ & $37,50 \%$ & $6,25 \%$ \\
FLT & $0,00 \%$ & $1,59 \%$ & $1,20 \%$ & $30,68 \%$ & $2,39 \%$ & $61,35 \%$ & $2,79 \%$ \\
TEC & $0,00 \%$ & $0,00 \%$ & $0,00 \%$ & $26,92 \%$ & $6,73 \%$ & $56,73 \%$ & $9,62 \%$ \\
ISP & $0,00 \%$ & $0,00 \%$ & $0,00 \%$ & $15,89 \%$ & $17,88 \%$ & $52,98 \%$ & $13,25 \%$ \\
FORM & $0,00 \%$ & $0,00 \%$ & $0,00 \%$ & $18,42 \%$ & $10,53 \%$ & $63,16 \%$ & $7,89 \%$ \\
TOTAL & $0,00 \%$ & $0,66 \%$ & $0,49 \%$ & $27,80 \%$ & $7,73 \%$ & $56,09 \%$ & $7,24 \%$ \\
\hline
\end{tabular}

Fonte: Dados de campo, 2011.

Embora pouco enfatizados, alguns conflitos entre os mundos comuns foram apontados nas entrevistas: (i) Mundo industrial versus doméstico: práticas domésticas definidas como obsoletas, não sendo promotoras de transformações sociais resultantes de metodologias de alto desempenho e impacto. (ii) Mundo industrial versus mundo da inspiração: pessoas que ingressam no setor por princípios da lógica da inspiração (criatividade, ruptura, espontaneidade) sentem dificuldades para atuar a partir de uma lógica industrial. (iii) Mundo cívico versus industrial: crítica à burocratização excessiva, à tecnocracia e à perda do pensamento coletivo, quando a organização visa somente à sua própria manutenção e sobrevivência no campo.

Na crítica reside um papel relevante da sociedade civil, que é o de questionar os movimentos de incorporação acrítica de princípios e práticas, visando à pluralidade do campo e à politização de sua atuação. Ela demonstra um caráter contra-hegemônico conectado com as possibilidades de democracia trazidas por Habermas (1985) e por Sousa Santos (2002), entre outros.

Enfim, no que se refere à segunda hipótese, pode-se afirmar que existem conflitos no campo, mas esses ainda são ínfimos em face das possibilidades e da necessidade de justificação e legitimação das OSC. E com isso a homogeneização do setor acontece com mais força, refletindo-se na incorporação de práticas que possam gerar maior aceitação/legitimidade.

\subsubsection{As passarelas entre os mundos comuns}

Como citado, a aproximação de diferentes lógicas pode resultar na construção de passarelas entre os mundos comuns (Boltanski e Thévenot, 2006). A terceira hipótese explora esse pressuposto, afirmando que passarelas entre os mundos comuns podem ser construídas por meio do diálogo, das redes e de coalizões duradouras, e estas poderão fortalecer certas justificações e ideais de legitimidade das OSC e do próprio campo. 
No discurso dos atores, verifica-se a existência de passarelas que dão origem a novos significados, objetos e práticas e que podem representar tendências em termos de novas justificações de legitimidade para o campo: (i) Mundos cívico e industrial: o foco nas causas pode gerar maior afirmação no espaço público e maior mobilização dos indivíduos e de recursos; (ii) Mundos cívico e doméstico: com a politização de alguns objetos e práticas tradicionalmente assistencialistas e com a criação de novas convenções e direitos; (iii) Mundos cívico e de projetos: com a utilização de redes sociais para mobilização social e política; (iv) Mundos doméstico, inspirado e industrial: apresentam-se nas relações de trabalho no campo, destacando-se em particular a prática do voluntariado, que passa a assumir características cada vez mais profissionais.

Segundo Boltanski e Thévenot (2006), para que esses compromissos construídos sejam duradouros, no entanto, o novo objeto gerado deve tornar-se indivisível, com uma identidade que não seja reconhecida, a não ser que os mundos comuns que lhe dão sentido estejam em conjunto. As OSC entrevistadas apresentaram alguns desses objetos híbridos em seus discursos, os quais são exemplificados no quadro 4.

Quadro 4

Termos que simbolizam passarelas no campo das OSC no Sul do Brasil

\begin{tabular}{|l|l|l|}
\hline \multicolumn{1}{|c|}{ Objeto } & $\begin{array}{c}\text { Mundos comuns em } \\
\text { compromisso }\end{array}$ & \multicolumn{1}{c|}{ Conceito } \\
\hline $\begin{array}{l}\text { Responsabilidade } \\
\text { Social }\end{array}$ & Industrial e Cívico & $\begin{array}{l}\text { "(...) corporações teriam a intenção de assumir os riscos sociais e ambientais } \\
\text { gerados por suas atividades produtivas e a capacidade de preveni-los" (Cattani } \\
\text { e Salmon, 2009:289). }\end{array}$ \\
\hline Economia Solidária & Mercantil e Cívico & $\begin{array}{l}\text { "(...) primazia da solidariedade sobre o interesse individual e o ganho material, } \\
\text { o que se expressa mediante a socialização dos recursos produtivos e a adoção } \\
\text { de critérios igualitários" (Laville e Gaiger, 2009:162). }\end{array}$ \\
\hline $\begin{array}{l}\text { Desenvolvimento } \\
\text { Sustentável }\end{array}$ & Industrial e Cívico & $\begin{array}{l}\text { "(...) desenvolvimento que satisfaz as necessidades do presente sem } \\
\text { comprometer a capacidade de as futuras gerações satisfazerem as suas } \\
\text { próprias necessidades" (Brüseke, 1994:30). }\end{array}$ \\
\hline
\end{tabular}

Fonte: Dados de campo (2011) e autores citados.

Estes três termos chamaram a atenção, pois são também trazidos por Chiapello (2011) como alternativas de justificação e geradoras de legitimidade diante das críticas ao sistema capitalista, em um processo de ressignificação desse sistema na atualidade. Como defende essa autora, as evidências da pesquisa demonstram que a relação de influência no campo das OSC do mundo industrial pode ocorrer de forma bidirecional, dando origem a novas justificações e fontes de legitimação.

Existem também outros termos que se apresentam como passarelas entre os mundos comuns, mas não apareceram com a mesma força no discurso dos atores que os termos anteriores, como: "certificado de filantropia" (mundo industrial e da inspiração), "relatório social" 
(mundo industrial e cívico), "banco comunitário" (mundo mercantil e cívico), "fundação comunitária" (mundo industrial e cívico), "capital social” (mundo mercantil e cívico) e "empreendedorismo social" (mundo mercantil e cívico).

Com isso, podemos confirmar a hipótese de que os atores constroem passarelas e pontes entre as diferentes lógicas de atuação que trazem novos significados ao campo, por meio do diálogo, das redes e de coalizões duradouras, e estas fortalecem novas justificações e ideais de legitimidade das OSC e do próprio campo.

\subsubsection{Os mundos predominantes e o isolamento de outras lógicas}

A hipótese de que existem lógicas predominantes no campo que dificultam a existência e isolam outros mundos comuns foi validada com as evidências das pesquisas. Nos resultados auferidos da análise frequencial das entrevistas dos atores do campo, observou-se que as lógicas dos mundos industrial e cívico predominam no discurso dos atores entrevistados, com maior influência prática da lógica industrial.

De acordo com Boltanski e Thévenot (2006), no mundo industrial, o principal objetivo da organização refere-se à sua continuidade. Por isso, técnicas e instrumentos que garantam essa sobrevivência são valorizados e os aspectos que possam significar ineficiência ou o fim da própria organização são desvalorizados.

A legitimidade, neste caso, depende de validação científica que corrobore com os resultados e a eficácia da organização, em uma dimensão pragmática, conforme Suchman (1995). Ela pode estar ligada também à dimensão moral da legitimidade, quando se percebe que essa instrumentalização é socialmente aceita.

Estas duas dimensões de legitimidade, segundo Suchman (1995), são reativas, elas pressupõem adaptação às pressões sociais e não geram transformação de convenções estabelecidas. Este processo pode resultar em isomorfismo e homogeneização do campo, predominando numa postura de adaptação que se sobrepõe à crítica e ao desvelamento das contradições.

A porcentagem relativa ao mundo cívico também se apresenta relevante. No entanto, percebe-se que essa lógica predomina quando os autores se referem a valores relacionados aos "Princípios Superiores Comuns" (PSC) e aos "Estados de Grandeza" (EG), mas que não mantêm coerência com as categorias que evidenciam a sua prática, tais como os "Modelos de Teste" (MT) e a "Lista de Objetos" (OBJ).

Relevante considerar que Boltanski e Thévenot (2006) apontam que o próprio funcionamento da sociedade moderna se baseia nos compromissos entre os mundos cívico e industrial e esses compromissos também aparecem no discurso dos atores quando eles se referem a aspectos como: (i) "as causas coletivas devem ser organizadas por meio de instituições para que sejam ouvidas"; (ii) "a mobilização social pode ser mais efetiva por meio de esforços organizacionais"; (iii) "a aproximação da capacidade produtiva e organizacional com a solidariedade coletiva pode resultar em novos direitos" e; (iv) "medidas que aumentam a eficiência dos serviços públicos são justificadas pela preocupação com o bem comum”. 
Dois movimentos podem estar associados a este processo: a politização e a humanização dos aspectos técnicos ou a tecnização da política e das relações pessoais. Embora seja possível verificar que os dois movimentos acontecem simultaneamente, as entrevistas apontam que o movimento mais forte é o da tecnização da política e das relações pessoais, num processo de adaptação.

Destaca-se o risco de isolamento de algumas OSC com atuação baseada no mundo cívico, por sua resistência e crítica aos testes do mundo industrial. Este isolamento faz com que as organizações que justificam sua atuação nos mundos em "Estado de Declínio e Queda" (EDQ) tenham dificuldade de se legitimar no campo: ou seja, o não reconhecimento da lógica faz com que ela não seja capaz de fornecer legitimidade. Desse modo, o acesso aos suportes necessários à sustentabilidade da OSC pode ser dificultado, influenciando diretamente na diminuição de seu poder de influência no campo.

As lógicas do mundo da inspiração e do mundo doméstico parecem perder espaço enquanto geradoras de legitimidade no campo e a lógica do mundo da fama quase não aparece no discurso dos atores. É interessante notar que essas lógicas que estão perdendo espaço fortalecem, junto com o mundo cívico, o que seria o Mundo da Vida, definido por Habermas (1985) como o espaço no qual a ação comunicativa se desenvolve com mais intensidade, sendo fundamental para o fortalecimento de uma esfera pública autônoma. Como destaca esse autor, o Mundo da Vida tem importante papel na transformação social e na manutenção da identidade e na autonomia da sociedade civil. Assim, a decadência dos mundos inspirado e doméstico no campo das OSC na região estudada, como geradoras de justificações, pode indicar uma valorização do Mundo do Sistema (fundado na racionalidade instrumental, estratégica ou normativa) em detrimento do Mundo da Vida.

\section{Considerações finais}

Esta pesquisa teve como objetivo buscar compreender as justificações dominantes que embasam a atuação e a existência das OSC no Sul do Brasil, conferindo-lhes legitimidade, de acordo com os atores representativos do campo.

Os resultados apontam que as dimensões da legitimidade que predominam nas OSC da região são a pragmática e a moral, que englobam os tipos de legitimidade de efetividade, de resultados e de adaptação às regras da sociedade. Essas dimensões da legitimidade têm por base a resposta às demandas dos stakeholders (Suchman, 1995) e estimulam a adaptação das organizações a padrões externamente estabelecidos, não fomentando, em geral, transformação e a concepção de novos padrões de legitimação.

Destaca-se que o contexto sócio-histórico atual coloca como preocupações centrais das OSC os processos de institucionalização e de mobilização de recursos, denotando uma racionalização do campo. Isso tem levado à difusão das técnicas industriais e de mercado na esfera da sociedade civil e ao enfraquecimento do seu papel político. Esse processo remete ao tenso encontro entre as esferas pública e privada, que produz, em muitos casos, a subordinação 
da primeira à segunda, o que fragiliza a política e a própria autonomia da sociedade civil. Esse movimento foi já evidenciado por diferentes autores como: (i) Hannah Arendt (1991), ao denunciar a ascensão do "social" que ocorre quando o mundo privado prevalece sobre o mundo público; (ii) por Bauman (2000), por meio da crítica feita ao controle do mercado nas políticas relacionadas à agenda de opções individuais, tomando o papel que antes pertencia às instituições políticas vigentes e; (iii) por Habermas (1985), com a invasão das racionalidades estratégica, instrumental e/ou normativa em esferas nas quais predominava a racionalidade comunicativa.

Como afirma Habermas (1985), o problema não reside no desenvolvimento industrial e tecnológico per se, mas sim na predominância dessa perspectiva como projeto humano, em detrimento das prerrogativas do Mundo da Vida. No caso das OSC parece que a sustentabilidade do campo pressupõe a convivência (nem sempre harmônica e sujeita à crítica) dos diferentes mundos comuns. A pluralidade de lógicas, antes de ser vista como algo ameaçador, pode ser encarada como uma peculiaridade e uma riqueza própria da nossa esfera pública.

Para afirmar essa pluralidade, parece importante que as OSC fortaleçam a dimensão cognitiva da legitimidade por compreensibilidade (Suchman, 1995). Nesta as organizações interagem proativamente em relação ao ambiente externo, na tarefa de fazer compreender a razão da sua existência, provendo as justificações necessárias para sua atuação e tendo papel ativo na criação de novos modelos culturais. Nesse sentido, ressalta-se a relevância da crítica e do conflito, necessários para o processo de justificação das organizações e para a legitimação das mesmas (Boltanski e Thévenot, 2006), fortalecendo a democracia (Sousa Santos e Avritzer, 2002).

Isso implica que as OSC se percebam como atores políticos, atuando na esfera pública com ações que impactem para além de suas relações diretas e que influenciem os demais setores da sociedade. Espaços para a reflexão sobre valores e práticas do campo, buscando compreender as suas lógicas de justificação, de modo a influenciá-las, também se tornam relevantes. Por outro lado, para que a democracia tenha papel imperativo na sociedade civil brasileira, parece também relevante que políticas públicas para o campo levem em conta essa diversidade e heterogeneidade do mesmo. Assim, possibilitar-se-á a coexistência e a construção de passarelas entre diferentes mundos comuns.

Alguns questionamentos relevantes, no entanto, não foram respondidos nesta pesquisa e poderão estimular a reflexão de pesquisadores e profissionais envolvidos com o campo: como criar brechas para que as diferentes justificações sejam reconhecidas e os diversos papéis desempenhados pela sociedade civil sejam legitimados? Como as organizações que têm sua lógica de justificação em estado de declínio podem se fortalecer sem se adaptarem acriticamente às novas lógicas predominantes no campo? Como favorecer a crítica, promovendo julgamentos inspirados no diálogo entre os mundos e não apenas na estrita aplicação de justificações definidas externamente? Como as organizações que possuem papel de regulação no campo podem fomentar esta mudança? Essas organizações querem protagonizar esta mudança?

Estas questões são fruto da complexidade do tema em questão e representam pistas e lacunas que esta pesquisa faz emergir. Reconhecemos que este estudo teve um papel precur- 
sor na região Sul do Brasil, mas foi apenas um primeiro passo; ainda há um caminho longo que deve ser trilhado para uma mais completa compreensão do fenômeno. Com isso, esperase que este trabalho possa estimular os caminhantes interessados a buscar outras trilhas que possam contribuir para o reconhecimento da sociedade civil brasileira e para o seu fortalecimento, em prol da democracia.

\section{Referências}

ABRAMOVAY, Ricardo. A rede, os nós, as teias. Tecnologias alternativas na agricultura. Rev. Adm. Pública, v. 34, n. 6, p. 159-177, nov./dez. 2000.

ALVES-MAZZOTTI, Alda J.; GEWANDSZNAJDER, Fernando. O método nas ciências naturais e sociais: pesquisa quantitativa e qualitativa. 2. ed. São Paulo: Pioneira, 1999.

ANDION, Carolina. A gestão no campo da economia solidária: particularidades e desafios. Revista de Administração Contemporânea, v. 9, n. 1, p. 79-101, jan./mar. 2005.

ANDION, Carolina. Atuação das ONGs nas dinâmicas de desenvolvimento territorial sustentável no meio rural de Santa Catarina: os casos da Apaco, do Centro Vianei de educação popular e da Agreco. Tese (doutorado em ciências humanas) — Centro de Filosofia e Ciências Humanas, Programa Interdisciplinar em Ciências Humanas, Doutorado Sociedade e Meio Ambiente, Universidade Federal de Santa Catarina, Florianópolis, 2007.

ANDION, Carolina; SERVA, Maurício. Por uma visão positiva da sociedade civil: uma análise histórica da sociedade civil organizada no Brasil. Cayapa. Revista Venezolana de Economía Social, v. 7, n. 7, p. 7-24, jan./jun. 2004.

ARENDT, Hannah. A condição humana. 10. ed. Rio de Janeiro: Forense, 1991.

ATACK, Iain. Four criteria of development NGO legitimacy. World Development, v. 27, n. 5, p. 855864, maio 1999.

BARDIN, Laurence. Análise de conteúdo. Lisboa: Edições 70, 1977.

BAUMAN, Zygmunt. Em busca da política. Rio de Janeiro: Jorge Zahar, 2000.

BOLTANSKI, Luk; CHIAPELLO, Ève. O novo espírito do capitalismo. São Paulo: WMF Martins Fontes, 2009.

BOLTANSKI, Luk; THÉVENOT, Laurent. On justification: economies of worth. Nova Jersey: Princeton, 2006.

BOLTANSKI, Luk; THÉVENOT, Laurent. The sociology of critical capacity. European Journal of Social Theory, v. 2, n. 3, p. 359-377, ago. 1999.

BROWN, David L.; JAGADANANDA, Lloyd. Civil society legitimacy and accountability: issues and challenges. CIVICUS and The Hauser Center for Nonprofit Organizations. Massachussets: John F. 
Kennedy School of Government, Harvard University, 2007. Disponível em: <www.civicus.org/ new/media/LTA_ScopingPaper.pdf > . Acesso em: 4 ago. 2009.

BRÜSEKE, Franz J. O problema do desenvolvimento sustentável. In: CAVALCANTI, Clovis (org.). Desenvolvimento e natureza: estudos para uma sociedade sustentável. 1994. Biblioteca Virtual de Ciências Sociais da América Latina e Caribe (Clacso). Disponível em: <www.clacso.org/wwwclacso/ espanol/html/biblioteca/fbiblioteca.html>. Acesso em: 7 fev. 2010.

CATTANI Antonio D.; SALMON, Anne. Responsabilidade social das empresas. In: CATTANI, Antonio et al. (Org.). Dicionário internacional da outra economia. Coimbra: Almedina, 2009. p. 162-168. Disponível em: <www.jornaldomauss.org/periodico/wp-content/uploads/2009/06/dicionariointernacional-da-outra-economia.pdf >. Acesso em: 15 jun. 2011.

CHIAPELLO, Ève. L'innovation sociale comme réponse aux critiques du capitalisme. In: POR UNE NOUVELLE MONDIALISATION: LE DÉFI D’INNOVER. 7 e 8 abr. 2011, Montréal. Crises. Mimeografado.

CIVICUS. Turning principles into practices: a guide to legitimacy, transparency and accountability, 2010. Disponível em: < http://lta.civicus.org/download/Turning\%20principles\%20in\%20practice. pdf > . Acesso em: 10 fev. 2010.

COHEN, Jean L.; ARATO, Andrew. Civil society and political theory. Massachusetts: MIT Press, 1997.

COLLINGWOOD, Vivien. Non-governmental organisations, power and legitimacy in international society. Review of International Studies, v. 32, n. 3, p. 439-454, jul. 2006. Disponível em: <www. un-ngls.org/orf/pdf/Non-governmental\%20organisations_power\%20and_legitimacy_in_international_society.pdf $>$. Acesso em: 5 maio 2010.

DAGNINO, Evelina. Sociedade civil, espaços públicos e a construção democrática no Brasil: limites e possibilidades. In: DAGNINO, Evelina (Org.). Sociedade civil e espaços públicos no Brasil. Rio de Janeiro: Paz e Terra, 2002. p. 279-303.

DAMATTA, Roberto. A casa e a rua. Rio de Janeiro: Guanabara, 1991.

EDWARDS, Michael. Introdução. In: EDWARDS, Michael; GAVENTA, John (Ed.). Global citizen action: perspectives and challenges. Colorado: Lynne Rienner Publishers, Inc., 2000.

FERNANDES, Rubens. C. Privado porém público: o terceiro setor na América Latina. Rio de Janeiro: Civicus, 1994.

GIBELMAN, Margaret; GELMAN, Sheldon. A loss of credibility: patterns of wrongdoing among nongovernmental organizations. Voluntas: International Journal of Voluntary and Nonprofit Organizations, v. 15, n. 4, p. 355-382, dez. 2004. Disponível em: <www.springerlink.com/content/ p1561q440t56101v/fulltext.pdf>. Acesso em: 20 ago. 2009.

GODOI, Christiane K.; MATTOS, Pedro L. C. L. de. Entrevista qualitativa: instrumento de pesquisa e evento dialógico. In: GODOI, Christiane K.; BANDEIRA-DE-MELO, Rodrigo; SILVA, Anielson B. Pesquisa qualitativa em estudos organizacionais: paradigmas, estratégias e métodos. São Paulo: Saraiva, 2006. p. 301-323. 
GOHN, Maria da Glória. Conselhos gestores e participação sociopolítica. 3. ed. São Paulo: Cortez, 2007.

HABERMAS, Jürgen. The theory of communicative action. v. 2. Lifeworld and system: a critique of functionalist reason. Boston: Beacon Press, 1985.

IBGE. INSTITUTO BRASILEIRO de GEOGRAFIA e ESTATÍSTICA. As fundações privadas e associações sem fins lucrativos no Brasil 2005. Estudo realizado em parceria com Ipea, Abong e Gife. 2008. Disponível em: <www.ibge.gov.br/home/estatistica/economia/fasfil/2005/fasfil.pdf>. Acesso em: 20 jan. 2011.

JOHNS HOPKINS. Global civil society, dimensions of the nonprofit sector. Baltimore: The Johns Hopkins Institute for Policy Studies, 1999. p. 393-410. Disponível em: < http://ccss.jhu.edu/wp-content/ uploads/downloads/2011/08/Global-Civil-Society-I.pdf> . Acesso em: 9 fev. 2010.

KRIEGER, Morgana G. M. Legitimidade das organizações da sociedade civil na região Sul do Brasil: uma análise da percepção dos atores do campo à luz da teoria das grandezas. Dissertação (mestrado) - Centro de Ciências da Administração e Socioeconômicas, Universidade do Estado de Santa Catarina, Florianópolis, 2011.

LANDIM, Leilah. A invenção das ONGs: do serviço invisível à profissão sem nome. Tese (doutorado) - Programa de Pós-Graduação em Antropologia Social do Museu Nacional, Universidade Federal do Rio de Janeiro, Rio de Janeiro, 1993. Disponível em: < http://empreende.org.br/pdf/ ONG's,\%20OSCIP'S\%20e\%20Terceiro\%20Setor/A\%20inven\%C3\%A7\%C3\%A3o\%20das\%20ONGs. pdf>. Acesso em: 12 jun. 2010.

LANDIM, Leilah. Múltiplas identidades das ONGs. In: HADDAD, Sérgio (Org.). ONGs e universidades: desafios para a cooperação na América Latina. Rio de Janeiro: Abong; Fundação Peirópolis, 2002. p. 17-50.

LAVILLE, Jean-Louis; GAIGER, Luiz I. Economia solidária. In: CATTANI, Antonio D. et al. (Org.). Dicionário internacional da outra economia. Coimbra: Almedina, 2009. p. 162-168. Disponível em: <www.jornaldomauss.org/periodico/wp-content/uploads/2009/06/dicionario-internacional-daoutra-economia.pdf $>$. Acesso em: 15 jun. 2011.

LEHR-LEHNARDT, Rana. NGO legitimacy: reassessing democracy, accountability and transparency. Cornell Law School Inter. University graduate student conference papers. 2005. Disponível em: < http://scholarship.law.cornell.edu/cgi/viewcontent.cgi?article=1020\&context=lps_clacp > . Acesso em: 22 ago. 2009.

LÉVESQUE, Benoît. Contribuição da nova sociologia econômica para repensar a economia no sentido do desenvolvimento sustentável. Revista de Administração de Empresas, v. 47, n. 2, p. 49-60, abr./jun. 2007.

LEVÉSQUE, Benoît; BOURQUE, Gilles; FORGUES, Eric. La nouvelle sociologie économique. Paris: Desclée de Brouwer, 2001.

MCGANN, James; JOHNSTONE, Mary. The power shift and the NGO credibility crisis. International Journal of Not-for-profit Law, v. 8, n. 2, p. 65-77, nov. 2005. Disponível em: <www.icnl.org/research/journal/vol8iss2/ijnl_vol8iss2.pdf>. Acesso em: 22 nov. 2009.

NUNES, Edson de O. A gramática política do Brasil. Rio de Janeiro: Zahar, 1994. 
OSSEWAARDE, Ringo; NIJHOF, André; HEYSE, Liesbet. Dynamics of NGO legitimacy: how organising betrays core missions of INGOs. Public Administration Development, v. 28, n. 1, p. 42-53, fev. 2008.

QUADROS, Teresinha. Mudanças na economia mundial e impacto nas ONGs. Bahia Análise e Dados, v. 7, n. 4, p. 17-25, mar. 1998. Disponível em: <www.nuppead.unifacs.br/artigos/impactoongs. pdf >. Acesso: 12 abr. 2010.

SCHERER-WARREN, Ilse. Das mobilizações às redes de movimentos sociais. In: SCHERER-WARREN, Ilse. Redes de movimentos sociais. São Paulo: Loyola, 1993. p. 32-33.

SCHERER-WARREN, Ilse. Sociedade e Estado. Brasília, v. 21, n. 1, p. 109-130, jan./abr. 2006.

SCHERER-WARREN, Ilse; KRISCHKE, Paulo J. (Org.). Uma revolução no cotidiano? Os novos movimentos sociais na América do Sul. São Paulo: Brasiliense, 1987.

SLIM, Hugo. By what authority? The legitimacy and accountability of non-governmental organizations. In: THE INTERNATIONAL COUNCIL ON HUMAN RIGHTS POLICY INTERNATIONAL MEETING ON GLOBAL TRENDS AND HUMAN RIGHTS - BEFORE AND AFTER SEPTEMBER 11, jan. 2002, Geneva. Disponível em: <www.jha.ac/articles/a082.htm>. Acesso em: 16 set. 2009.

SOUSA SANTOS, Boaventura (Org.). Democratizar a democracia: os caminhos da democracia participativa. Rio de Janeiro: Civilização Brasileira, 2002.

SOUSA SANTOS, Boaventura; AVRITZER, Leonardo. Introdução: para ampliar o cânone democrático. In: SOUSA SANTOS, Boaventura (Org.). Democratizar a democracia: os caminhos da democracia participativa. Rio de Janeiro: Civilização Brasileira, 2002. p. 39-82.

SUCHMAN, Mark C. Managing legitimacy: strategic and institutional approaches. The Academy of Management Review, v. 20, n. 3, p. 571-610, jul. 1995.

TAYLOR, Marylin; WARBURTON, Diane. Legitimacy and the Role of UK third sector organizations in the policy process. Voluntas: International Journal of Voluntary and Nonprofit Organizations, v. 14. n. 3, p. 321-338, set. 2003.

VEDDER, Anton (Org.). NGO involvement in international governance and policy: sources of legitimacy. Nijhoff Law Specials v. 72. Leiden-Boston: Martinus Nijhoff Publishers, 2007. Disponível em: <http://f3.tiera.ru/1/genesis/645-649/649000/572a3e1dc8d56ade4e22ab970d92512d>. Acesso em: 3 ago. 2010.

Morgana G. Martins Krieger é mestre em administração e diretora do Instituto Nossa Ilhéus. E-mail: morgana.krieger@gmail.com.

Carolina Andion é doutora em ciências humanas. Professora do Departamento de Administração Pública do Programa de Pós-Graduação em Administração e diretora de extensão do Centro de Ciências da Administração e Socioeconômicas (Esag) da Universidade do Estado de Santa Catarina (Udesc). Líder do Núcleo de Pesquisa e Extensão em Inovações Sociais na Esfera Pública (Nisp) cadastrado no CNPq. E-mail: andion.esag@gmail.com. 